\title{
A framework for developing justice reinvestment plans for crime prevention and offender rehabilitation in Australia's remote indigenous communities
}

\section{Glenn Desmond Dawes \& Andrea Davidson}

To cite this article: Glenn Desmond Dawes \& Andrea Davidson (2019): A framework for developing justice reinvestment plans for crime prevention and offender rehabilitation in Australia's remote indigenous communities, Journal of Offender Rehabilitation, DOI: 10.1080/10509674.2019.1621417

To link to this article: https://doi.org/10.1080/10509674.2019.1621417

进 Published online: 13 Jun 2019.

Submit your article to this journal

Џ Article views: 8

View Crossmark data ¿ 


\title{
A framework for developing justice reinvestment plans for crime prevention and offender rehabilitation in Australia's remote indigenous communities
}

\author{
Glenn Desmond Dawes ${ }^{\mathrm{a}}$ and Andrea Davidson ${ }^{\mathrm{b}}$ \\ a James Cook University College of Arts Society and Education, Alligator Creek, Australia; \\ ${ }^{b}$ New South Wales Department of Juvenile Justice, Sydney, Australia
}

\begin{abstract}
Initiatives targeting Indigenous overrepresentation in Australia's criminal justice systems have been largely ineffectual. Justice reinvestment has been touted as a potential panacea. This article provides a framework for developing justice reinvestment plans with communities, based on a qualitative research project focusing on levels of crime and recidivism in two remote Indigenous communities. The framework is a hybrid design, informed by a crime analysis, action research, narrative data analysis and a culturally informed Indigenous research paradigm. It is argued that justice reinvestment can be successfully implemented which empowers Indigenous peoples to identify the causes of crime based on place-based solutions.
\end{abstract}

\section{KEYWORDS}

Community-based rehabilitation; diversion; crime prevention; evidence based practice; offender re-entry; justice reinvestment

\section{Introduction}

\section{Indigenous overrepresentation in Australia's criminal justice system}

Despite the fact that Australia's first nations peoples constitute only 3\% of the national populace, they make up over a quarter of the country's prison population and are more likely to have interactions with the criminal justice system than any other cohort (Australian Bureau of Statistics [ABS], 2012, 2015). With 78\% of incarcerated Indigenous offenders evidencing prior conviction and a quarter of Indigenous peoples released from prison in Australia reoffending within six months, a chronic cycle of recidivism underpins the nations Indigenous overrepresentation problem (Bryant and Willis, 2008; ABS, 2015). Developing and implementing crime prevention and offender rehabilitation initiatives that can serve to break the cycle of perpetual Indigenous overrepresentation in the criminal justice system continues to be a matter of national priority in Australia.

CONTACT Glenn Desmond Dawes glenn.dawes@jcu.edu.au E James Cook University College of Arts Society and Education, Alligator Creek, 4816, Australia.

Color versions of one or more of the figures in the article can be found online at www.tandfonline.com/wjor.

(C) 2019 Taylor \& Francis Group, LLC 
In this article, the word Indigenous is used to refer to Australia's first nations peoples, made up of over 600 different cultural and language groups that represent the oldest continuous culture of peoples on earth (Raphael, Swan \& Martinek, 1998). Through forced colonization that commenced in 1788, Australia's first nations people were dispossessed from their homelands, had their cultures actively dismantled, and were extensively denied basic human rights. Consistent with other countries where first nations people survive within a dominant colonized society, Indigenous Australians continue to be adversely impacted by the legacy of unilateral dispossession and dismantling of the country's first nations. In the field of criminal justice, perpetual impacts of colonization recognized as critically linked to Indigenous overrepresentation include: intergenerational trauma, racism and discrimination, historic social and cultural destruction and contemporary social marginalization, and cumulative disadvantage (Cunneen \& Tauri, 2016).

The rate of overrepresentation of Indigenous Australians in the nations criminal justice system has been increasing since the 1980s, with rapid escalation noted across the course of the present decade (ABS, 2014, 2015). However, geographic distribution of Indigenous overrepresentation is not uniform, with Indigenous offender data revealing exacerbation in remotely located communities more so than any other location (Hudson, 2013). Indeed, despite the fact that only $24 \%$ of Indigenous Australians live in remote areas, national data shows the majority of top 10 offender locations in each state and territory are located in rural and remote areas (Hudson, 2013). Moreover, in Queensland the most chronic and costly offenders are recognized as residing in remote and very remote locations such as the two communities where the research was conducted (Allard, Chzanowski and Stewart, 2012).

Although mapping and analyzing crime trends and recidivism statistics aides in identifying the extent of offending in such locations, identifying the factors that underpin and perpetuate marked exacerbation in offending amongst certain peoples, and developing a service system that can respond accordingly, is far more complex. In a seminal paper on the topic of reducing reoffending amongst Indigenous Australian's prepared for this journal, Day (2003) outlined in detail the argument that assumptions underpinning scientific and empirical approaches to identifying "what works" in offender rehabilitation, are "likely to be seen by those from Indigenous backgrounds as inappropriate" (p. 4). Prior to and since this time, academics leading the emerging field of Indigenous criminology have similarly argued that the central assumption that research regarding "what works" in terms of rehabilitation for one culture or peoples is generalizable to another, is fundamentally flawed (Dudgeon \& Pickett, 2000; Cunneen and Tauri, 2016). 


\section{From what works to "what works for whom"}

In his article for this journal 15 years ago, Day (2003) drew on the words of McCleod (2001), to provide an aspirational vision for where future solutions to Indigenous overrepresentation in Australia might lie: "Often the first steps in initiating change involve not direct action, but creating a framework for understanding what is happening and how things might be different" (p. 256).

Since this time, a number of Australian government and research reports have similarly advocated for alternative responses to addressing offending and offender rehabilitation amongst Indigenous Australians, with a focus on the need for specialized approaches for remote Indigenous communities in particular. For example, both the Doing Time-Time for Doing (Australian Government, 2011) and Many Ways Forward (Australian Government, 2004) report concur that coordinated community-based services are required to provide well-resourced holistic support to combat Indigenous overrepresentation. The Many Ways Forward report also specifically advocates for a whole of government place-based response in regional and remote areas (Australian Government, 2004). This position is supported in the report Doing Time-Time for Doing, which recommends the provision of community-specific programs to address the underlying socioeconomic disadvantage contributing to the exacerbation of crime rates in remote Indigenous communities (Australian Government, 2011).

Equally, Richards, Rosevear, and Gilbert (2011) proposed that focusing crime prevention programs on matters of concern to individual Indigenous communities would secure community support and buy-in. Moreover coordinated approaches to developing and supporting the implementation of localized solutions is recognized as potentially the most effective method of addressing issues linked to the perpetuation of crime in any given place:

Crime is most effectively prevented when criminal justice and social policies work concurrently with locally or community organized partnerships to create safer cities. Policy development at government, NGO (nongovernment organization) and other agency levels must focus on how to create this environment collectively. (Bahn, 2011, pp. 261-262)

In achieving this aim, the importance of self-determination through enhanced community control around developing and implementing crime prevention strategies, has been emphasized alongside the provision for a more equitable allocation of resources. For example, Beresford (2012) proposes that disrupting the cycle of overrepresentation in any given location requires money to be diverted away from punitive measures, such as prisons, and directed back towards diversionary and rehabilitative programs that will provide positive outcomes for whole communities. A justice 
reinvestment approach has been widely touted as a potential solution to achieving this aim.

\section{Justice reinvestment: A logical and pragmatic solution}

A recent study into Australian prisons estimates it costs $\$ 109,500$ (Australian dollars) per year to keep an individual in prison, placing Australia as the fifth highest country in the world in terms of expenditure on prisons (Busnell, 2017). It is extensively recognized that prisons have limited success for rehabilitating Indigenous offenders (Brown, 2010). Thus, there have been numerous calls to explore alternative strategies for reducing crime at the community level by addressing the factors that contribute to offenders entering and remaining in the criminal justice system. Indeed, the numerous government and research reports cited in the previous section of this article argue that community-based programs that adopt selfdeterminant approaches to addressing crime, are likely to be far more effective in terms of reducing high levels of crime and recidivism in any given community.

Justice reinvestment is an approach to Indigenous crime prevention and offender rehabilitation that is widely recognized as having the potential to overcome the shortcomings of mainstream models (Schwartz, Brown and Cunneen, 2017; Schwartz and Cunneen, 2014; Calma, 2009). Justice reinvestment offers a place-based approach to addressing justice and social level drivers of offending and incarceration, by focusing on rehabilitative approaches that respond to the precipitants of exacerbated crime specific to any given community (Allison and Cunneen, 2018). The major premise of justice reinvestment is the redirection of funds that are centrally administered by government agencies (e.g., Justice Departments) to local communities, which are aware of the variable causes of crime in their location and therefore most able to identify and influence crime prevention and rehabilitative solutions (Fox, Albertson, \& Warburton, 2011). Furthermore, justice reinvestment has been successfully trialed in overseas jurisdictions, including the United States and United Kingdom and has been recognized as a contemporary, evidence-based response to the high economic, social, and personal costs of incarceration (Allison and Cunneen, 2018).

\section{Justice reinvestment in Australia}

In analyzing the potential benefits of justice reinvestment in the Australian context, Schwartz and Cunneen (2014) emphasized its potential applicability to addressing the country's Indigenous overrepresentation problem. They contend that justice reinvestment empowers the tailoring of justice 
responses to target the distinct needs of communities with perpetually high incarceration and recidivism rates. Through a tailored, fit for purpose approach, it is argued that justice reinvestment can address deep sociohistoric drivers of crime in any given place, whilst also affording Indigenous peoples enhanced human rights outcomes. Thus, it could be argued that in addition to addressing crime on a local level, justice reinvestment has the potential to positively contribute to Indigenous reconciliation on a broader national scale.

This resonates with the position of Calma, who asserted that applying policies of localism to addressing Indigenous overrepresentation in Australia through justice reinvestment would be a more appropriate and effective solution than mainstream methods, as justice reinvestment approaches: "Focus more on individuals as part of their neighbourhood, seeing their behaviour as part of a pattern and seeking solutions that [provide] improvements to both individuals and the community" (Calma, 2009, p. 28).

Allison and Cunneen (2018) identified an additional secondary benefit of justice reinvestment which aligns with current government policies aimed at addressing marginalization and social exclusion. Indeed, justice reinvestment offers an approach that addresses social inequality through the process of empowering and transforming disadvantaged communities. Similarly, in reviewing the promise of justice reinvestment in Australia, Wood (2014) suggested relocating a proportion of funds from correctional to community programs, would assist in addressing the social costs of prisons on broader community functioning.

Although justice reinvestment has been broadly touted as a potential panacea to Australia's Indigenous overrepresentation problem, there is nonetheless other commentators who critique the potential of justice reinvestment to effectively address mass incarceration and exacerbated recidivism amongst Indigenous Australians. The potential challenges associated with developing and implementing justice reinvestment have been highlighted, particularly in remote Indigenous contexts, where overrepresentation in the criminal justice system is most chronically exacerbated. For example, Hudson argues that remoteness may have implications for ease of statistical data and crime mapping, as well as programmatic resourcing and service delivery (Hudson, 2013). Hudson also questions whether justice reinvestment programs are any different from existing programs in remote Indigenous communities, many of which have not been evaluated to ascertain their success in reducing the continuing high incarceration and recidivism rates. Hudson concludes that new initiatives like justice reinvestment "involve a relatively high degree of risk as there is no guarantee on the outcome" (Hudson, 2013, p. 17). 
Furthermore, there is considerable debate about how the model should be adapted for the Australian context and particularly for remote Indigenous communities. This position is highlighted in a report on justice reinvestment by the Australian Senate Legal and Constitutional Affairs References Committee (2013), which states: "The committee is conscious that the direct implementation of an approach from the United States is problematic and indeed, may fail if not appropriately adapted to Australian conditions" (p. 60).

In supporting the proposal to adopt justice reinvestment, the Australian Social Justice Commissioner highlighted that to be effective, the approach must be buttressed by policies of localism, which aim to devolve power away from centralized government responses to empowerment at the grassroots community level.

Similarly, Schwartz (2010) noted: "Due to the focus on local ownership, all justice reinvestment initiatives depend on the commitment, participation and support of communities in which they are implemented" (p. 11).

In response to this observation, it is noted that few studies exist that actually document how the principles of justice reinvestment could be adapted to facilitate remote Indigenous communities to take ownership and "buy in" to developing and implementing alternative communitybased solutions to crime. The current article attempts to fill this void by providing a framework for developing justice reinvestment plans with communities, based on analysis of the outcomes and the methodological process associated with researching the causes and potential solutions to chronic levels of crime and recidivism in two remote Indigenous communities.

\section{Building a framework for developing justice reinvestment plans with remote indigenous communities}

The framework outlined in the following sections of this article had its genesis in an applied two-year qualitative research project. The project was conducted as a component of the Australian federal government's "Breaking the Cycle" initiative and was implemented across two remote communities in Far North Queensland, Doomadgee and Mornington Island.

The outcomes of this research project are extensively outlined in the Australian Government commissioned research report, Keeping On Country-Recidivism Research Report, authored by Dawes (2016) and the associated peer reviewed paper, Keeping On Country: Understanding and Responding to Crime and Recidivism in Remote Indigenous Communities authored by the collective research team (Dawes, Davidson, Walden, \& Isaacs, 2017). In building the framework for developing justice 
reinvestment in remote Indigenous communities, the authors were also extensively guided by recommendations and discussion contained within the numerous aforementioned government agency reports, as well as key texts and literature pertaining to the evolution of justice reinvestment in the Australian context, Indigenous research paradigms and decolonizing research approaches more broadly.

Although the development of the framework was based on the "real world" experience of developing justice reinvestment strategies with two remote Indigenous communities, in the absence of evaluation, the framework is acknowledged as evidence-informed and aspirational rather than empirically based. Nonetheless, due to the nature of development, it is argued that the framework offers a contextually and research informed approach to identifying what place-based services, programs and rehabilitation initiatives are appropriate to put forward as a justice reinvestment plan for any given remote Indigenous community in Australia.

\section{The proposed framework}

The proposed justice reinvestment framework involves three interrelated stages, which are based on a distillation of the assumptions of justice reinvestment broadly, as well as contemporary policy and program design principles. The three stages of the justice reinvestment framework proposed are summarized next.

\section{Stage 1: Mapping crime and social data to identify needs}

Crime and social data sets are overlaid and analyzed in combination, to provide a profile of crime and social disadvantage in any given neighborhood. High crime rates specific to neighborhoods or community areas, are considered alongside data relating to cumulative disadvantage specific to that place.

Offense and offender data should cascade to provide an indication of offending trends, including dominant offense types, and an indication as to where returning prisoners are likely to be located upon release from prison. Offender data should also be used to map the numbers of people subject to formal justice system supervision upon reentering any given community.

Combining crime and social data sets enables identification of broad based community needs and potential policy options for service delivery targets within the community of focus. The aim is to map and analyze this data in parallel to identify potential service targets for the justice reinvestment plan. It is argued that these targets represent community specific needs, which if addressed through a justice reinvestment plan, offer a more 
effective means of reducing crime in that location than large scale mainstream justice responses that have a well-established record of perpetuating overrepresentation.

A researcher with the necessary skills and capabilities should oversee mapping of crime and social data. However, data gathered and mapped through this process should be actively shared with community members in order to empower local understandings of crime and cumulative disadvantage in that place and engage informed narratives as to potential placebased solutions.

\section{Stage 2: Action research to identify the causes of crime and develop preventative and rehabilitative solutions}

Community consultation and engagement is the most critical component of developing a justice reinvestment plan for any given location. This step is oriented around identifying the causes of crime from the perspective of community members, as well as identifying, and wherever possible trialing, effective place-based solutions.

It is argued that action research represents a suitable and effective methodology to achieve this aim. The rationale for using action research is to gather and analyze data, and develop place-based solutions for inclusion in a justice reinvestment plan that relates to the participatory, value-based, democratic practice implicit to the approach. Moreover a central tenant of action research is effectively contributing to social change through examining specific problems in the context in which they occur. It is beyond the scope of the current article to detail the evidence base pertaining to the suitability of action research, however this topic is extensively examined in the extended research paper that describes this project (Dawes et. al., 2017). In addition to outlining the case as to the suitability of action research for developing justice reinvestment plans, this article also demonstrates how an action research methodology can be applied in a way that is congruent with Indigenous ontology and epistemology and informed by the axiology and research agenda of Indigenous communities themselves (Dawes et. al., 2017). Therefore as was observed in this study, in the case of Indigenous communities, the action research approach to identifying local solutions to crime, has the potential to overcome community fear regarding research being done on rather than with Indigenous peoples.

\section{Stage 3: Evaluation}

The final step of the framework involves evaluating justice reinvestment initiatives to ascertain their success in addressing the incidence of crime in 
any given location. This stage is critical in terms of producing measurable outcomes that gauge whether the justice reinvestment plan should continue in its current format, or whether modification or new initiatives are required (Calma, 2009).

Historically, programs aimed at addressing the overrepresentation of Indigenous people in the criminal justice system have not been effectively evaluated. Particularly striking is the marked absence of research pertaining to contextual viewpoints informing evaluation of programs in any given place. Indeed in Australia, the observation of Day (2003) in this journal 15 years ago still stands, in that there continues to be: "No way of evaluating the likely effectiveness of any rehabilitation programs for Indigenous offenders. We simply do not know whether existing mainstream rehabilitation programs are effective or ineffective with Indigenous offenders" (p.12).

The authors contend that in order to address this gap, it is critical that evaluation studies examine the effectiveness of programs or initiatives targeting Indigenous crime and overrepresentation through an Indigenous research paradigm, with methodology grounded in Indigenous ontology and epistemology and informed by the axiology of Indigenous communities themselves. We therefore argue that the evaluation framework for any justice reinvestment plan should be individually tailored in partnership with the communities themselves, as a component of initial implementation of the justice reinvestment plan (i.e., alongside the roll out of initiatives).

Whilst this necessarily precludes a wholly prescribed approach, we argue that a community informed evaluation framework would typically apply a cultural and contextual lens to examining a common set of outcome elements, comprising of:

1. An analysis of community "buy-in" to the justice reinvestment plan and the implementation of programs and initiatives outlined in the plan;

2. Uptake and participation in programs and initiatives, including analysis of: programmatic referrals and engagement; flexibility and responsiveness of engagement and reengagement; programmatic drop-out; programmatic completion;

3. Impact of programs and initiatives, including analysis of: crime, incarceration and recidivism statistics; and, qualitative information pertaining to individual desistence from crime; quantitative and qualitative analysis of any change to the social and economic drivers associated with crime (as identified through stages one and two).

In order to ensure locally informed evaluation measures are captured, community perceptions in relation to the following core elements should 
also be integrated into an agreed evaluation framework for the justice reinvestment programs and initiatives, prior to their implementation:

1. What will success look like?

2. How will the community know a program/initiative is taking the right approach to addressing the particular outcomes target?

3. How will we identify what should change about a program or how we might improve it?

4. How will we identify gaps in the justice reinvestment plan, or other programs and initiatives we could introduce to strengthen the program?

In order to truly contextualize evaluation and capture the potential broader social outcomes of the justice reinvestment plan we argue that ethnographic analysis will be equally as important as quantitative analysis of crime, recidivism and incarceration data.

\section{Applying the framework to develop justice reinvestment plans for two remote indigenous communities}

In citing Allen (2007), Fox et al. (2011) emphasized, "Justice reinvestment starts from a universal criminological truth, that people in prison are not drawn in equal numbers from all neighbourhoods" (p. 122).

The argument in favor of establishing justice reinvestment in Australia's remote Indigenous communities is compelling. The remainder of this article will provide an integrated case study demonstrating the application of the first two stages of the framework outlined above to develop justice reinvestment plans across two such communities, namely, Doomadgee and Mornington Island, located in the isolated region known as the Gulf of Carpentaria, in Far North Queensland.

Detailed background pertaining to these communities can be found in the two extended research papers related to this study (Dawes, 2016; Dawes et. al., 2017). In summary, residents of these two communities, are incarcerated at a rate amongst the highest per capita of any given neighborhood in Australia. Moreover data indicates a link between social disadvantage and high rates of criminal offending. Suffice to say the rationale for establishing justice reinvestment plans in these two communities is undeniable. The following section outlines the development of a justice reinvestment plan for these communities through a stage focused discussion.

\section{Stage 1: Mapping crime and social data to identify needs}

To identify needs through crime and social data mapping, the research team drew on two key sources, the Queensland Police Service (2015) and 
the Dropping off the Edge Report (2007; 2015), a study examining location based disadvantage in Australia. An information sharing agreement was established with the Queensland Police Service, who provided regional and district crime statistics, whilst the publicly available Dropping off the Edge Report provided reporting of social disadvantage against $21 \mathrm{key}$ indicators. Figure 1 provides a graphical representation of the mapping of this combined crime and social data, whilst Figure 2 maps localized offender data.

Social data for the state of Queensland identified the communities of Doomadgee and Mornington Island experience the most extreme forms of cumulative disadvantage. Moreover, a comparison of this data between 2007 and 2014, demonstrated rising disadvantage. The social indicators noted as highly exacerbated included: young adults not engaged in employment or study; reduced opportunities for long term unemployment; unemployment; prison admissions; criminal convictions and low-family income.

Statewide offender data revealed that the Mt Isa local government area (which includes the communities of Mornington Island and Doomadgee) was the fourth highest Indigenous prisoner location in the state. Localized offender data revealed Mornington Island offenders were primarily ages 20-29, whilst Doomadgee had a far greater spread of offender age from 10-39, with 10-20-year-olds marginally dominant.

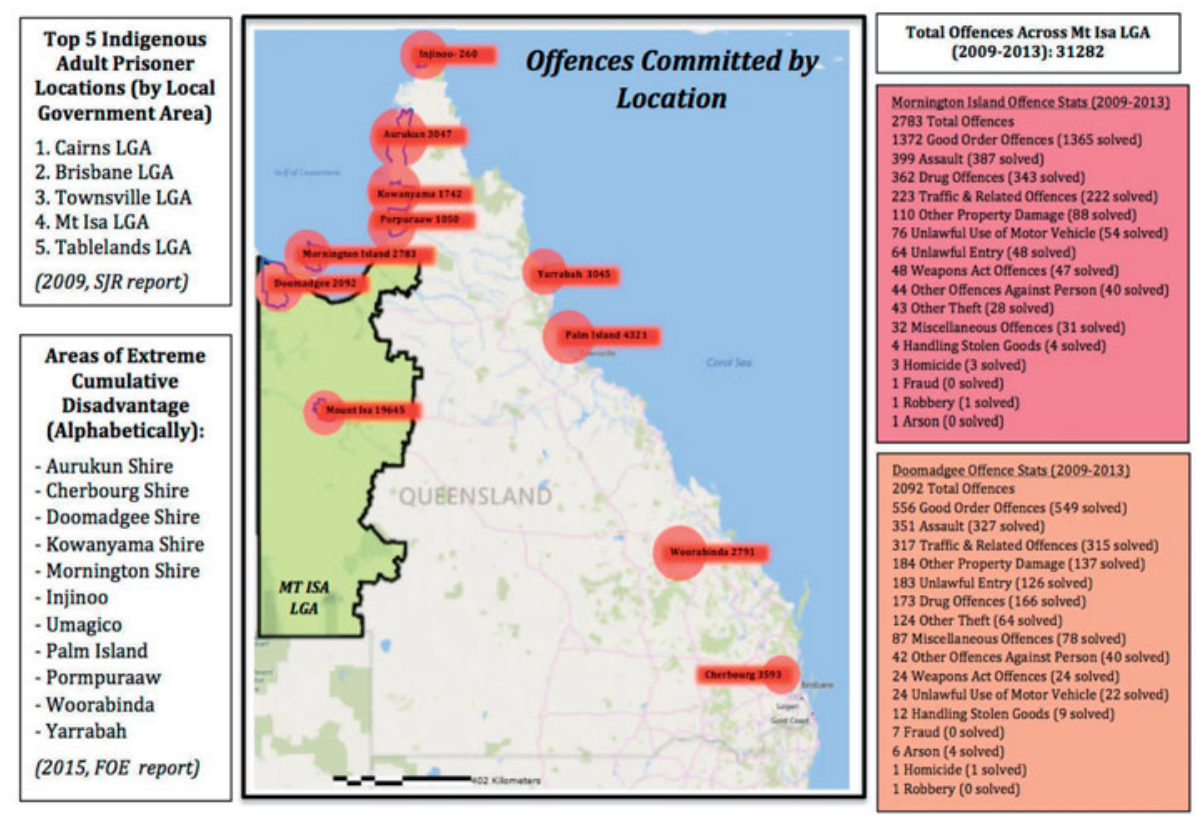

Figure 1. Data Mapping for Doomadgee and Mornington Island (2009-2013)- Offense Focus. 

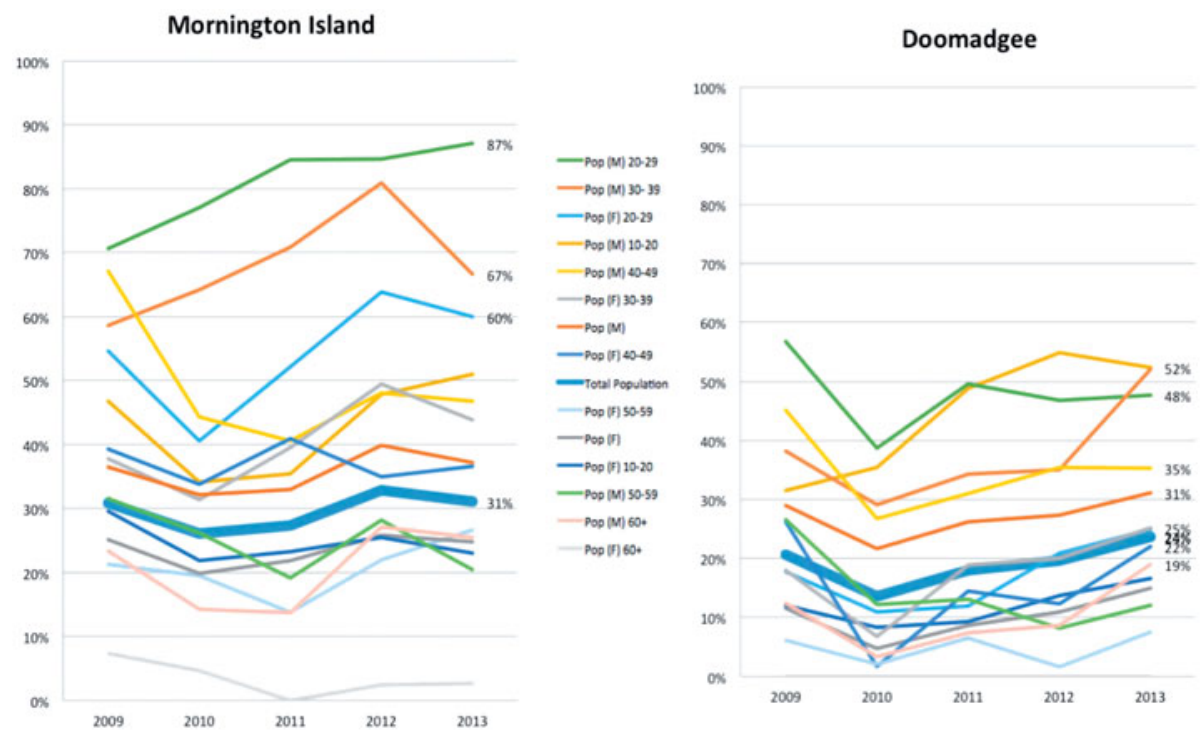

Figure 2. Data Mapping for Doomadgee and Mornington Island (2009-2013)- Offender Focus.

Local crime data revealed that in Doomadgee there had been an overall increase in offenses against the person and also noted that the number of assaults with domestic violence indicators had risen over the same period. On Mornington Island an increase in property crime and recorded liquor offenses was observed, as well as a concurrent trend in breach of domestic violence orders alongside a slight decrease in overall assaults.

The combined mapping output documented in Figures 1 and 2, and the observational narrative outlined, were used as the springboard for community engagement and discussion regarding the needs and potential targets for justice reinvestment.

\section{Stage 2: Action research to identify crime prevention and rehabilitative solutions}

\section{Methodology}

A project team of both Indigenous and non-Indigenous specialists collectively established an action research methodology, which was both closely aligned with principles of justice reinvestment and decolonizing Indigenous research paradigms. Detailed background pertaining to the evidence base underpinning the design of the research methodology can be found in the research paper authored by this team, entitled: Keeping On Country: Understanding and Responding to Crime and Recidivism in Remote Indigenous Communities (Dawes et. al, 2017). 
The methodological design put community members at the forefront of the research process through engagement that sought to identify social problems from the communities' perspective and identify pragmatic "grass roots" solutions. A participatory framework was adopted whereby community people worked as co-researchers alongside the research team. This ensured community perspectives were embedded in reflexive identification of the complex issues contributing to criminal behavior and potential pragmatic solutions.

The methodology examined the underlying causes of crime and recidivism through narrative and collaborative processes that accounted for the experience and insight of three primary cohorts, namely: individual offenders, family members of offenders and community agencies responsible for supporting offenders. Data collection targeted these three cohorts and was analyzed through the contextually informed lens of the local Indigenous researchers and participants at numerous rolling consultations.

Initiatives and strategies proposed were trialing immediately wherever possible, both to provide a timeliness to bringing about change and to strengthen the evidence case for the solutions proposed at the conclusion of the undertaking. These outcomes enhanced community buy-in to the research itself, as well as the impetus for change and interest in being involved in the implementation of solutions.

\section{Community engagement and recruitment of participants}

The research team arranged regular community information sessions and rolling consultations that engaged the community around the aims and perceived outcomes of the research. Updates were provided around progress and data collection, and community input was sought in relation to methodological design, interpretation of data and the outcomes of the research (i.e., the justice reinvestment plan). These meetings and consultation were held throughout the two-year research cycle, with the research methodology and analysis of results iteratively altered to reflect the participatory nature of the approach.

The two Indigenous researchers facilitated the recruitment of the former offenders and families of offenders. The project coordinator was responsible for recruiting the third cohort of participants, employees of government and nongovernment organizations that delivered services to individuals who had offended. These organizations included health care organizations, parole officers, health and well- being personnel and small business employers. The times and places for interviews was flexible to accommodate maximum participation. 


\section{Data collection}

Semistructured qualitative interview questions were developed informed by rolling consultations with community reference groups such as the men's and women's groups, Indigenous elders and Indigenous corporations at each site. The non-Indigenous researchers worked collaboratively with the two Indigenous researchers to develop the interview questions for each cohort to ensure they were culturally appropriate and community informed. In addition, the non-Indigenous member of the research team participated in cultural awareness and orientation training to ensure that the rights and sensitivities of the research participants were understood and respected.

Three cohorts of interview subjects were selected based on the following criteria:

1. Recidivist offenders who had previously been placed in detention or prison, and committed crimes while under the influence of alcohol or illegal substances;

2. Family members of recidivist offenders (as per criteria outlined above); and

3. Employees of agencies within the community who worked with offenders on their return to the community postprison.

In addition to structured interviews, in excess of sixty field interviews were conducted with individuals who were reluctant to be involved in a structured interview process, but were happy to have their input recorded in the researchers' field journals. Anecdotal interviews were also conducted within prison settings due to restrictions placed on the use of recording devices.

\section{Offender interviews}

A total of 20 individual interviews were conducted (10 at each site), ranging from 40-60 min in duration. Interviews were held at an office at the wellbeing center of each community or at an alternative location nominated by the interviewee.

Questions targeted psychosocial history, as well as history of drug and alcohol use. Interviewees were also asked to identify barriers to desisting from crime after returning from prison. Finally, each respondent was asked about potential solutions to prevent crime and assist former prisoners to desist from crime. Whilst questions were targeted across these key areas, the narrative was free flowing in order to elicit maximum engagement.

A sample of the interview questions included: 
1. Can you tell me about the first time you when you were charged with a crime?

2. How did you feel when you had to leave your family because you were sentenced to a term in prison?

3. What could be done in your community to stop people from returning to prison?

\section{Family member interviews}

A total of 20 interviews (10 at each site) between 30 and $60 \mathrm{~min}$ in duration were conducted with the partners or parents of recidivist offenders. These interviews were conducted at each of the Wellbeing Centers to ensure that the privacy of each person was respected. A sample of the interview questions included:

1. How is your family affected when your partner returns to prison? (economically, socially, personally).

2. How does the household change when your partner returns from prison?

3. What would you suggest could be done in the community so that the family is not separated when your partner goes to prison?

\section{Community agency interviews}

Individual interviews were conducted with 10 government and nongovernment agencies across both sites. Participants included service managers, probation and parole officers, youth justice workers, mental health practitioners, employment officers, as well as Indigenous representatives from the Women's and Men's Groups at each location. The sample questions for these interviews are listed below:

1. What do you think are the greatest challenges for your organization in assisting former prisoners and their families to reintegrate back to the communities postprison?

2. How effectively does your organization work with other agencies to assist people to desist from further offending?

3. How further resources could your agency use to assist former offenders and their families?

\section{Analysis of data pertaining to the causes and precipitants of crime and recidivism}

At the completion of the data collection interviews were transcribed and transferred to the NVIVO qualitative data processing computer program, 
which aided in the analysis of data. NVIVO analyzed transcripts to identify major themes and patterns, which were triangulated against crime and social mapping data, to identify the precipitants of crime and the challenges faced by exprisoners when they reenter their communities.

In addition to matrices identifying major themes, this process produced a series of case studies that highlighted both the diversity and commonality of experiences of people across both communities. The major themes and case studies identified were instrumental in guiding the researchers and community members in building a justice reinvestment plan.

The major themes identified as contributing to crime and impacting upon prisoner's successful reintegration back into their communities were: lack of employment or training opportunities due to the stigma of having a criminal conviction, breaching parole conditions, perceived harassment by police, and the resultant negative emotional and economic impacts on families.

A dominant theme identified as militating against desisting from crime was the common perception that prison was a normalizing experience or a rite of passage associated with becoming a man. Interestingly, family members and elders identified that whilst this was the perception amongst young men, in fact the prison experience only served to reduce men's selfesteem and their traditional role as providers for their families, as described by one elder:

A lot of men come back from prison and they don't have their place in the family. Like their traditional place. Like they can't have jobs so they feel like they can't provide so it makes them feel hopeless. You see them with their heads down, they don't feel like men anymore. (Male exoffender, age 34)

When asked about the greatest hurdles to overcoming the tendency to persist with offending a common theme was identified in relation to difficulties in finding employment when returning home. Most offenders stated that they possessed skills from previous work experience as well as certificates for working with heavy machinery in the mining and construction industries, which should have potentially positioned them for a place in well-paid positions within local industries such as mining. However, a major impediment identified by exoffenders who tried to reconnect with such employment was the waiting time for positions and on boarding processes, which produced increased stressors on the individual and increased the likelihood of relapsing back into crime: "I don't want to sit on the island all day with nothing to do and work for small money. ... This really worried me because it's no good just sitting around all day I need something to do" (Male exoffender, age 23).

Other exoffenders found reentry to the job market difficult due to institutional barriers attached to their criminal histories. For example, several men 
stated that they had obtained interviews with government institutions such as schools and hospitals only to find that they could not obtain a Queensland government blue card, required for employees to work in places where young people are present. Prison records were also seen as reinforcing stigma for returned offenders:

Of course, finding a job is one of the first things you look for when you get out of prison. It's too hard to get a job in our community because the first thing they're going to look at is have you got a criminal history? Sorry no job. (Male exoffender, age 36)

Successful reintegration was seen as frequently undone by breaching parole conditions soon after their release from prison. Pressure from family or peers to drink alcohol while on parole was cited as a factor that led to the breach of parole conditions for a high number of participants. Individuals were aware of their parole conditions and the outcomes for breaching parole. However, they admitted to often making the wrong choices and relapsing back to their former habits under pressure. In addition, it was suggested that family members and friends were often not aware of these parole conditions and the impact that it had on their loved ones:

When the family asks you to drink and you say; "I'm on parole." But the family will keep going and then it's up to you. You have to make that choice. You want to drink and go back to jail? You have to think about it. Are they going to write me this letter down there while I'm in jail a long time? (Male exoffender, age 21)

A further contributing factor for returning to prison related to failing to attend designated appointments with parole officers. While some interviewees cited failure to report due to family reasons, others cited that the reporting regime lacked sufficient flexibility to allow people working at the nearby mines to attend meetings. This employee explained that his roster at the mine would not allow him the time to attend a parole meeting, which put him at risk of returning to prison:

I rang them (parole) and they said, "You are a bit late." I said I was supposed to ring you yesterday but when you are down in a pit you can't use the phone ... I landed back in jail again because I never reported. (Male exoffender, age 56)

The reentry process was frequently described as difficult due to increased scrutiny by police. Respondents reported that they were often unfairly targeted by police, particularly when they were in public spaces:

You know when you come from jail the policeman he don't like you so they pick on you. Even when you are not doing things. You sitting there with family drinking. For them they say it is not really responsible for me to do what other family doing. (Male, exoffender age 20)

Interviews with family members and community agencies also identified a theme of family problems and disruption within families when males 
returned from prison. Interview data highlighted that families suffer from dislocation when males leave and return to the community, which affects the social emotional and economic well-being of the family unit. One agency representative described the effects on young children as:

If it's a male that goes to jail, the mothers are at home and she's intoxicated just every day. The kiddies are there and I feel real sorry for them. They need help and that's when Child Safety get involved which totally splinters the family unit. (NGO manager, age 41)

The participatory research design allowed exoffenders, family members and community agencies to identify the major obstacles which prevent individuals from desisting from further crime. The ethnographic data highlights that Indigenous communities are very aware of the factors that contribute to recidivism which is a major milestone in the process of implementing a community response from a justice reinvestment perspective. The following section illustrates that Indigenous communities also have potential solutions that have the potential to be implemented through a justice reinvestment approach.

\section{Analysis of data pertaining to identifying solutions to crime and recidivism}

Individuals from each cohort were asked to offer suggestions about the most appropriate solutions to crime and recidivism for their community.

While there were a number of suggestions for change, the most cogent solution offered by the offender and family cohorts was the introduction of reintegration bush-camps. It was proposed by these community members that individuals who returned from prison should be taken to "on country" camps situated outside the community, from where they could be assisted to gradually reintegrate into the community township. The logic behind the on-country camps was to allow returning prisoners to spend a transitional period within the vicinity of the township to reengage with traditional culture and reconnect with cultural expectations aligned with desistence from crime, and to prepare them for a gradual reentry back into the township environment. All family members, elders and exoffenders were in agreement that bush camps had the potential to short circuit the recidivism cycle and assist former offenders to desist from crime through rediscovery and identification with culture, and strengthening of personal and familial identity by reconnecting with traditional activities and roles, such as hunting and fishing, while being mentored by elders.

Overwhelmingly, agency providers recommended that they needed to work together more closely to support people upon their reentry. Investing in more community-based support programs was viewed as the most appropriate strategy. Emphasis was placed on the fact programs were 
needed that did not require offenders to leave the communities and return to prison, in order to avoid disrupting the lives of their families and promote building the capacity to function appropriately within the community.

Agency providers overwhelmingly offered their support for the notion of on-country bush camp, and identified the additional advantage was the potential for individuals to receive specific interventions and support from community-based professionals and agencies prior to reentry into the township. It was proposed that this could be achieved through access to programs which assisted former offenders in obtaining skills-based training in relation to maintaining pro-social behaviors aimed at reducing stress, addressing anger management, improving emotional regulation and resiliency, negotiating interpersonal conflict, communication skills, responsibility taking and victim empathy.

A number of Elders also saw an added advantage of this model, where the 'on country' bush-camps could also be accessed by young people who were at risk of being involved in crime, which could be a way of breaking the cycle of intergenerational crime through reconnection with their cultures values and traditions. One elder stated:

Most of them they just hang around town, doing drugs and that. Most people don't take them out bush and that they don't know their culture, they don't have respect for their elders so they just end up in jail.

Family members of former prisoners identified that on country bushcamps would have the added advantage of ensuring that they could maintain contact with their loved ones through periodic visits to the camps. This would overcome the major obstacle associated with a family member being removed from the community and having limited contact due the expense of travel from the community to prisons for families who wished to visit their loved ones.

In addition, it was proposed the model would provide greater opportunities for former offenders to establish engagement and receive support from community-based men's or women's groups prior to reentry into the township. Community service providers identified that the proposed bush-camps could also provide structured opportunities for inter-agency co-operation so that effective transitional arrangements could be put in place to address the risk factors linked to reoffending. For example, exoffenders could learn skills to make them potentially more job ready while on country, which would assist in addressing some of the risk factors such as unemployment that have been identified as contributing to reoffending upon return to the township.

Finally, community members also viewed bush camps as being potentially beneficial as intervention programs for former offenders who had 
reentered their community, but were showing signs of relapsing into former destructive behaviors through drug and/or alcohol abuse. It was envisaged that people who were identified as being at risk of further offending could voluntarily reengage with the bush-camp programs until they were ready to return to the community.

\section{Stage 3: Evaluation}

Although a justice reinvestment plan was established for each community, funding for comprehensive implementation has not as yet been forthcoming. As such the evaluation component of the framework remains an aspirational goal and is as yet untested.

\section{Discussion}

Despite the absence of dedicated funding and program structure, it is notable that a number of initiatives included in the justice reinvestment plans developed have nonetheless been implemented. Indeed, at the conclusion of the study, the male Indigenous member of the research team, along with a number of men included in the original offender interview cohort, established a "Keeping on Country" support group (specifically dedicated to supporting desistence from crime). The group meets weekly and engages in a monthly on country camp. Similarly, both Indigenous researchers have reported that as a result of the research study itself there is an enhanced sense of community recognition that successful reintegration can be aided by reconnection to country. In support of this claim researchers have noted that many families now actively take young men back on to country upon their return from prison. Similarly families will now often actively remove young men from the township to on country locations when circumstantial stress escalates risk of reoffending (e.g., difficulties in intimate partner relationships; commence drinking alcohol or engaging in gambling). More recently the notional support for on country bush-camps has gained momentum with a number of families offering to designate their traditional lands as potential sites for this initiative. While a dedicated reintegration bush-camp program has yet to be actively established and evaluated, the groundswell for such an initiative has been maintained.

Other initiatives trialed as a component of establishing the justice reinvestment plans have also been continued by community agencies despite the absence of funding. For example, family video conferencing visits first introduced as a proactive solution to family disconnection during periods of incarceration continue to be provided by community agencies. Also, the wellbeing centers in each community were able to obtain funding for a 
dedicated transition wellbeing officer, despite the absence of funding for the broader justice reinvestment plan. We argue that these outcomes demonstrate that even in the worst case scenario that a justice reinvestment plan developed by the community is not backed with dedicated funding, the process of developing the plan nonetheless affords many community benefits.

Moreover, it is notable that community members and the Indigenous researchers have suggested that implementing stages one and two of the framework alone has resulted in emancipatory outcomes. Specifically, it has been suggested that as a result of the nature of the methodology, community members perceived their voices had been elevated. It has been reflected by community members who have not historically had the opportunity to express their opinions about their interactions with the criminal justice system, that they have finally gained a sense of having "had their say" and "being heard" (direct quotations from a community Elder).

Despite the stated benefits of employing the proposed framework from an Indigenous perspective, there are a number of limitations which should be identified. While there was support for the project from both the Doomadgee and Mornington Island communities there were difficulties in recruiting female participants for the offender cohort interviews, which impeded analysis from a female perspective. Additionally, the male offender cohort consisted predominantly of men over the age of thirty. A future study of this kind would therefore benefit from obtaining the perceptions of younger people to compare their experiences with their older counterparts. A further limitation is that it is difficult to generalize whether other Aboriginal or Torres Strait Islander communities would "buy into" a justice reinvestment approach due to the diversity of lived experiences of people in distinctly different contexts.

\section{Conclusion}

The aim of this article has been was to outline and demonstrate application a framework for developing justice reinvestment plans in remote Indigenous communities. Through meeting this aim we sought to show that Indigenous people in remote communities crippled by a cycle of crime and recidivism, have the ability to develop a justice reinvestment plan and build community support for the approach.

In addition to demonstrating this is possible, this study also reaffirmed the fact that existing approaches to dealing with chronic crime through incarceration incur high economic, social and cultural costs and do little in rehabilitate people. This study also reiterated that the problem is exacerbated when exoffenders return to their communities and fail to be provided with meaningful, 
contextually informed support that addresses endemic social disadvantage, including unemployment, unsuitable and limited accommodation and appropriate therapeutic services. In addition, this study confirmed the process of reintegration is made more difficult due to the stigmatization of individuals who are perceived as criminogenic by other community members, as well as regulatory agencies such as the police.

Justice reinvestment has been championed as an alternative approach with recognized potential and applicability to remote Indigenous communities, where overrepresentation continues to paralyze community progress. This article has attempted to move one step further in progressing the call for justice reinvestment by responding to the dearth of work demonstrating that Indigenous communities can be engaged to buy in to a justice reinvestment approach by adopting an Indigenous research paradigm and action research based approach to building justice reinvestment plans.

The data obtained from the participants across both sites during the course of this study supports observations made by prominent Aboriginal leaders such as Tom Calma, who argued that a justice reinvestment approach will only work if community people are given the opportunity to articulate the problems they face and provide pragmatic solutions to the problem. We argue that in so doing they are also provided with the opportunity to buy into the solutions as Calma proposes and are compelled to take ownership of responses to problems such as crime and recidivism through grassroots self-determination.

\section{References}

Australian Bureau of Statistics (2012). Australian demographic statistics. Canberra, Australia: Australian Capital Territory.

Australian Bureau of Statistics (2015). Recorded crime - Offenders, 2015-16 (No. 4519.0). Canberra, Australia: Australian Capital Territory.

Australian Government (2004). House of Representatives Standing Committee: Many ways Forward: Report of the Inquiry into Capacity Building and Service Delivery in Indigenous Communities. Canberra, Australia: Government Printing Press.

Australian Government (2011). House of Representatives Standing Committee: Indigenous Youth in the Criminal Justice System. Canberra, Australia: Government Printing Press.

Allard, T., Chzanowski, A., \& Stewart, A. (2012). Targeting crime prevention to reduce offending: Identifying communities that generate chronic and costly offenders. Trends \& Issues in Crime and Criminal Justice. Woden, Australia: Australian Institute of Criminology.

Allen, R. (2007). 'From restorative prisons to justice reinvestment', in: R. Allen and V. Stern (Eds.), Justice reinvestment: A new approach to crime and justice, London, UK: International Centre for Prison Studies.

Allison, F., \& Cunneen, C. (2018). Justice reinvestment in Northern Australia. Cairns Institute Policy Paper Series. Cairns, Australia: James Cook University. 
Bahn, S. (2011). Community safety and recidivism in Australia: Breaking the cycle of reoffending to produce safer communities through vocational training. International Journal of Training Research, 9(3), 261-266. doi:10.5172/ijtr.9.3.261

Beresford, Q. (2012). Crime, justice and Aboriginal youth. In Q. Beresford, G. Partington \& G. Gower (Eds.), Reform and resistance in Aboriginal education (Revised ed., pp. 235-260). Crawley, Australia: UWA Publishing.

Brown, D. (2010). The limited benefit of prison in controlling crime. Current Issues in Criminal Justice, 22(1), 137. doi:10.1080/10345329.2010.12035873

Bryant, C., \& Willis, M. (2008). Risk factors in Indigenous violent victimisation. Technical Background Paper (30); Canberra, Australia: Australian Institute Criminology.

Busnell, A. (2017). Australian criminal justice costs: An international comparison. Canberra, Australia: Institute of Public Affairs.

Calma, T. (2009). Social justice report 2009. Sydney, Australia: Australian Human Rights Commission

Cunneen, C., \& Tauri, J. (2016). Indigenous criminology. Bristol, UK: Policy Press.

Dawes, G. (2016). Keeping on country: Doomadgee and Mornington Island recidivism research report: Breaking the Cycle Programme. Canberra, Australia: Australian Capital Territory.

Dawes, G., Davidson, A., Walden, E., \& Isaacs, S. (2017). Keeping on country: Understanding and responding to crime and recidivism in remote Indigenous communities. Australian Psychologist, 52(4), 306-315. doi:10.1111/ap.12296

Day, A. (2003). Reducing the risk of re-offending in Australian indigenous offenders. Journal of Offender Rehabilitation, 37(2), 1-15. doi:10.1300/J076v37n02_01

Dudgeon, P. \& Pickett, H. (2000). Working with Indigenous Australians: a handbook for psychologists. Perth, Australia: Gunada Press.

Fox, C., Albertson, K., \& Warburton, F. (2011). Justice reinvestment: Can it deliver more for less? The Howard Journal of Criminal Justice, 50(2), 119-136. doi:10.1111/j.14682311.2010.00654.x

Hudson, S. (2013). Panacea to prison? Justice reinvestment in Indigenous communities. Policy Monographs No. 134. Canberra, Australia: Centre for Independent Studies.

McLeod, J. (2001). The politics of counselling. In J. McLeod (Ed.), An introduction to counselling. 238-262. London: Open University Press.

Queensland Police Service (2015). Crime Statistics Northern Districts (2013-2017). Brisbane, Australia: Queensland Police Services Statistical Division.

Raphael, B., Swan, P., \& Martinek, N. (1998). Intergenerational aspects of trauma for Australian Aboriginal people. In International handbook of multigenerational legacies of trauma. 327-339. New York, NY: Springer.

Richards, K., Rosevear, L., \& Gilbert, R. (2011). Promising interventions for reducing Indigenous juvenile offending (Vol. 10). Sydney, Australia: Indigenous Justice Clearinghouse.

Senate Legal and Constitutional Affairs References Committee (2013). Value of a justice reinvestment approach to criminal justice in Australia. Canberra, Australia: Commonwealth of Australia.

Schwartz, M., Brown, D., \& Cunneen, C. (2017). Justice reinvestment - brief 21. Canberra, Australia: Indigenous Justice Clearinghouse, Australian Institute of Criminology.

Schwartz, M., \& Cunneen, C. (2014). Redressing over-incarceration, addressing human rights: what can justice reinvestment do in Australia?. Right Now: Human Rights in Australia 
Schwartz, M. (2010). Building communities, not prisons: Justice reinvestment and Indigenous over-imprisonment. Australian Indigenous Law Review, 14(1), 2-17. doi:jstor.org/stable/26423157

Wood, W. (2014). Justice reinvestment in Australia. Victims and Offenders, 9(1), 1-25. doi:10.1080/15564886.2013.860935 